Egypt. Acad. J. biolog. Sci., 2 (2): 111-118 (2009)

Email: egyptianacademic@yahoo.com

Received: 5/11/2009
A. Entomology

ISSN: 1687-8809

www.eajbs.eg.net

\title{
Response of the Mediterranean fruit fly, Ceratitis capitata (Wied.) and peach fruit fly, Bactrocera zonata (Saund.) to some food attractants
}

\author{
Sameh. A. Moustafa \\ Plant Protection Research Institute, Agricultural Research Center, Ministry of \\ Agriculture
}

\begin{abstract}
The mean captured adults of the Mediterranean fruit fly (MFF), Ceratitis capitata (Wiedemann) per trap per day (CTD) in the traps containing Glan, Pro-lure 2\%, Agrisense, Bioprox, Pro-lure 5\%, Amadene, Buminal, Norlan and Agrinal were $11.04,10.55,10.22,7.62,6.56,3.98,3.16,2.98$ and 1.89 , respectively. While, the effectiveness of the tested food attractants against the peach fruit fly (PFF), Bactrocera zonata (Saunders) adults comes in descending order as follows: Gla > Pro-lure $5>$ Pro-lure 2\% $>$ Bioprox $>$ Agrisense $>$ Agrinal $>$ Buminal $>$ Norlan and Amadene; however, the CTDs of these preparations were 0.60, 0.60, 0.51, 0.49, 0.42, $0.22,0.15,0.13$ and 0.13 , respectively.

The present results showed that, adding the pesticide, malathion to the food attractant preparations was obviously reduced the attractiveness of the lures to both MFF and PFF adults. All of the tested preparations were attracted MFF and PFF females with a significantly high numbers in comparison to males. Regression analysis illustrated that the tested food attractants exhibited high stability by the time passed, where the passed time had not any significant effect on the potentiality of the tested preparations.
\end{abstract}

Key Words: Mediterranean fruit fly, Ceratitis capitata, Bactrocera zonata, food attractants

\section{INTRODUCTION}

The peach fruit fly (PFF), Bactrocera zonata (Saunders) and Mediterranean fruit fly (MFF), Ceratitis capitata (Wiedemann) are the most dominant and serious pests on fruit orchards in the world. They severely attack of many fruit species such as; guava, peach, mango, citrus, apricot, fig and apple, in addition to some vegetables such as tomato, pepper and egg-plants as secondary hosts (Kapoor \& Agarwal, 1982; White \& Elson-Harris, 1992; El-Minshawy et al., 1999; Hashem et al., 2004 and Ghanim, 2009).

The larvae of the fruit flies feed on the pulp of ripe fruits forming tunnels inside them causing a great damage and make fruits unfavorable for marketing and exportation (White and Elson-Harris, 1992 and Borge \& Basedow, 1997). According to Syed et al. (1970); Pena et al. (1998) and Ghanim (2009) C. capitata and B. zonata causing a considerable damage in many fruit species.

Females of tephritid flies need certain amino acids as nutrition for developing their eggs and so they are attracted by the bait (Aluja, 1985). Buminal (5, 10 and 15\% concentrations) was superior in attracting MFF (Saafan, 2000 and Amin, 2003) and PFF adults (Ghanim, 2009). In addition, Norlan was one of the most effective attractants for PFF adults (Ghanim, 2009).

The protein hydrolyzate preparations (food attractants) were previously used as a bait in McPhail traps (Steyskal, 1977), and they captured a large number of both males and females of PFF and MFF (Anonymous, 1985 and Saafan 2005). Catches of 
MFF and PFF by olfactory stimulants in attractant traps can be used to monitoring their populations and for predicting the infestation level (Ghanim, 2009). In addition, the bait application technique (BAT) is a widely used technique for controlling fruit flies; deploys spots of protein bait mixed with insecticide, were attracted and killed adult fruit flies (Roessler, 1989; Amin, 2003; and Saafan, 2005).

So, the present study based on field experiments covered the following topics:

- Evaluate the efficiency of some food attractants against MFF and PFF adults.

- Influence of mixed the insecticide malathion on its efficacy.

- Evaluate the stability of the attractants under field conditions.

\section{MATERIALS AND METHODS}

The present experiment was carried out in guava (Psidium guajava) orchard (about two feddan) located in the Experimental Farm, Faculty of Agriculture, Mansoura University. It was conducted during the period from the $2^{\text {nd }}$ till $14^{\text {th }}$ of September 2006.

Eight protein hydrolyzate attractants (Agricince, Amaden, BioProx OL 4N, Buminal, Norlan AMPL, Glan AMD Agrinal, and Pro-Lure Plus) were evaluated under field conditions.

The efficacy of the above food attractants preparations was tested against the adult flies of the peach fruit fly (PFF), Bactrocera zonata (Saunders) and Mediterranean fruit fly (MFF), Ceratitis capitata (Wiedemann) as follows:

1. Using all of these attractants with $5 \%$ concentration, additionally Pro-Lure was used with $2 \%$ (according to the recommended dosage of the Co. Producer).

2. Using the same concentration of the tested food attractants mixed with $0.5 \%$ malathion (EC).

McPhail traps (McPhail, 1937) were used by putting about $200 \mathrm{ml}$ of each attractant per trap. Each treatment was replicated five times. All prepared traps were distributed in a completely randomized design. The distance between two adjacent traps was 15 meters and the traps were hanged at about $1.5-2$ meters in a shadow place of the trees. The traps were investigated every 3 days along a period of 15 days. Captured females and males of PFF and MFF were counted and recorded as CTD (capture/trap/day).

Statistical analysis was fulfilled by using one way analysis of variances (ANOVA) (CoStat, 1990), in addition to the regression analysis was done to the obtained data.

\section{RESULTS}

\section{Efficacy of the tested food attractants:}

\section{C. capitata adults:}

As shown in the figure (1), the obtained data indicated that MFF adults showed different degrees of preference to the different tested food attractants. Without adding pesticide, Glan, Pro-lure 2\% and Agrisense attracted the highest numbers of $C$. capitata adults with a mean CTD of 11.04, 10.55 and 10.22 adults. Amadene (CTD = $3.98)$, Buminal $(\mathrm{CTD}=3.16)$, Norlan $(\mathrm{CTD}=2.98)$ and Agrinal $(\mathrm{CTD}=1.89)$ represented another group that was significantly less preferable to MFF adults. While, 
Bioprox and Pro-lure 5\% recorded a moderate level of attractiveness (mean CTDs were 7.62 and 6.56 adults) with insignificantly different from the two former groups.

With respect to food attractants mixed with the pesticide, Pro-lure 2\% attracted the highest numbers of $C$. capitata adults. Amadene, Glan, Agrisense, Bioprox, Buminal, Pro-lure 5\%, Agrinal and Norlan represented second rank with significantly different from the above mentioned preparation. The mean CTD of these previously mentioned attractants after the tested period were 5.84, 2.69, 2.64, 2.58, 1.62, 1.44, 1.13, 1.07 and 0.07 adults, respectively (Fig., 1).

As clearly illustrated in the figure (1), adding pesticide to the food attractant preparations obviously reduced the attractiveness of the lures to MFF adults.

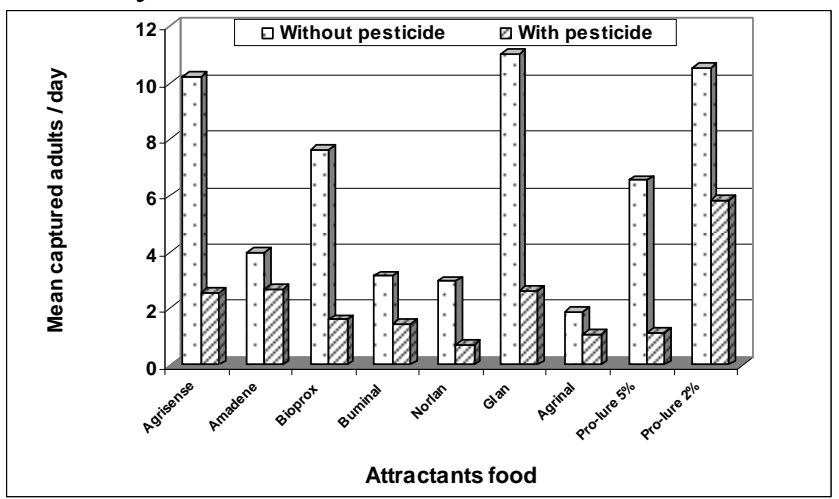

Fig. (1). Mean captured adults of C. capitata over 15 days by the tested food attractants (without and with insecticide) on guava orchards at Mansoura district.

L.S. $D_{\mathrm{P}=5 \%}=6.03$ (without pesticide) \& 2.91 (with pesticide)

\section{B. zonata adults:}

The data indicated that PFF adults showed no different degrees of preferability with different tested food attractants (Fig., 2). Without adding pesticide, Glan, Pro-lure (5 \& 2\%), Bioprox and Agrisense ranked the first group in attracting PFF adults with relatively high numbers although insignificant differences (mean CTDs were 0.60, 0.60, $0.51,0.49$ and 0.42 adults, respectively). Agrinal, Buminal, Norlan and Amadene represented second rank in attracting PFF adults with mean CTD of 0.22, 0.15, 0.13 and 0.13 adults, respectively. Statistically indicated no significant differences between the former two groups.

In addition, PFF adults showed no different degrees of preferability for the different tested food attractants mixed with malathion. However, the mean CTD of Glan, Buminal, Bioprox, Agrinal, Pro-lure $2 \& 5 \%$, Amadene, Agrisense and Norlan were 0.20, $0.18,0.18,0.16,0.13,0.11,0.04,0.04$ and 0.02 adults, respectively.

Adding malathion to the food attractant preparations obviously reduced the attractiveness of PFF adults (Fig. 2).

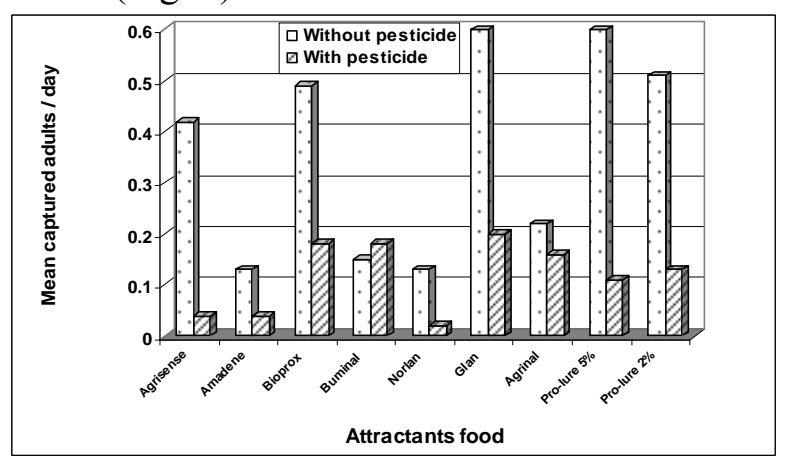

Fig. (2). Mean captured adults of B. zonata over 15 days by the tested food attractants (without and with insecticide) on guava orchards at Mansoura district.

L.S. $D_{\mathrm{P}=5 \%}=0.49$ (without pesticide) $\& 0.23$ (with pesticide) 


\section{Response of the tested fruit flies' sexes to food attractants: 1. C. capitata:}

The obtained data indicated that, C. capitata females have different degrees of preferability for the different tested preparations (Table, 1). The effectiveness of the tested food attractants against MFF adult females comes in descending order as follows: Pro-lure 2\% $>$ Glan $>$ Agrisense $>$ Bioprox $>$ Pro-lure 5\% $>$ Amadene $>$ Buminal $>$ Norlan and Agrinal, however the CTDs of these preparations were $9.80 \pm 1.93, \quad 9.73 \pm 1.88, \quad 9.15 \pm 3.99,6.98 \pm 1.33,6.09 \pm 0.82, \quad 3.42 \pm 0.39, \quad 3.38 \pm 0.77$, $2.29 \pm 1.14$ and $1.82 \pm 0.68$, respectively.

With respect to the attractiveness of the tested preparations against MFF adult males, these attractants come in descending order as; Glan $>$ Agrisense $>$ Pro-lure 2\% $>$ Bioprox $>$ Amadene $>$ Pro-lure 5\% > Buminal $>$ Norlan and Agrinal with a significantly low attracted numbers of males in comparison with females. However, the male CTDs of these preparations were $1.31 \pm 0.17,1.04 \pm 0.29,0.76 \pm 0.08$, $0.64 \pm 0.11,0.56 \pm 0.08,0.47 \pm 0.05,0.39 \pm 0.14,0.29 \pm 0.06$ and $0.07 \pm 0.00$, respectively (Table, 1).

\section{B. zonata:}

The obtained data indicated that, $B$. zonata females showed different degrees of preference for the different tested preparations (Table, 1). The effectiveness of the tested food attractants against PFF adult females comes in descending order as follows : Glan $>$ Pro-lure 2\% $>$ Bioprox $>$ Agrisense $>$ Pro-lure 5\% $>$ Agrinal $>$ Amadene $>$ Buminal and Norlan, however the CTDs of these preparations were

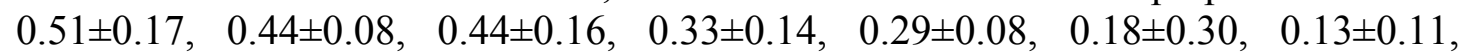
$0.13 \pm 0.14$ and $0.11 \pm 0.03$, respectively.

Table (1). Mean captured C. capitata and B. zonata females and males/trap/day (CTD) over 15 days by the tested food attractants on guava orchards at Mansoura district.

\begin{tabular}{|c|c|c|c|c|}
\hline \multirow{2}{*}{ Attractant } & \multicolumn{2}{|c|}{ MFF } & \multicolumn{2}{c|}{ PFF } \\
\cline { 2 - 5 } & $\begin{array}{c}\text { Females } \\
\text { Mean } \pm \text { S.E }\end{array}$ & $\begin{array}{c}\text { Males } \\
\text { Mean } \pm \text { S.E }\end{array}$ & $\begin{array}{c}\text { Females } \\
\text { Mean } \pm \text { S.E }\end{array}$ & $\begin{array}{c}\text { Males } \\
\text { Mean } \pm \text { S.E }\end{array}$ \\
\hline Agrisense & $9.15 \pm 3.99$ & $1.04 \pm 0.29$ & $0.33 \pm 0.14$ & $0.07 \pm 0.05$ \\
Amadene & $3.42 \pm 0.39$ & $0.56 \pm 0.08$ & $0.13 \pm 0.11$ & $0.00 \pm 0.00$ \\
Bioprox & $6.98 \pm 1.33$ & $0.64 \pm 0.11$ & $0.44 \pm 0.16$ & $0.04 \pm 0.03$ \\
Buminal & $3.38 \pm 0.77$ & $0.39 \pm 0.14$ & $0.13 \pm 0.14$ & $0.02 \pm 0.03$ \\
Norlan & $2.29 \pm 1.14$ & $0.29 \pm 0.06$ & $0.11 \pm 0.03$ & $0.02 \pm 0.03$ \\
Glan & $9.73 \pm 1.88$ & $1.31 \pm 0.17$ & $0.51 \pm 0.17$ & $0.09 \pm 0.06$ \\
Agrinal & $1.82 \pm 0.68$ & $0.07 \pm 0.00$ & $0.18 \pm 0.30$ & $0.04 \pm 0.03$ \\
Pro-lure 5\% & $6.09 \pm 0.82$ & $0.47 \pm 0.05$ & $0.29 \pm 0.08$ & $0.09 \pm 0.03$ \\
Pro-lure 2\% & $9.80 \pm 1.93$ & $0.76 \pm 0.08$ & $0.44 \pm 0.08$ & $0.07 \pm 0.05$ \\
\hline
\end{tabular}

With respect to the attractiveness of the tested preparations against PFF adult males, these attractants come in descending order as; Glan $>$ Pro-lure 5\%> Agrisense $>$ Pro-lure 2\% $>$ Bioprox $>$ Agrinal $>$ Buminal $>$ Norlan and Amadene with a significantly low attracted numbers of males in comparison with females. However, the male CTDs of these preparations were $0.09 \pm 0.06,0.09 \pm 0.03,0.07 \pm 0.05$, $0.07 \pm 0.05,0.04 \pm 0.03,0.04 \pm 0.03,0.02 \pm 0.03,0.02 \pm 0.03$ and $0.00 \pm 0.00$, respectively (Table, 1).

\section{Evaluate the stability of these attractants under field conditions:}

To evaluate the potentiality of the tested compounds as lures for MFF and PFF against time, regression analysis had been done. 
Data illustrated in the figure (3) showed the regression of the attractiveness of each tested food attractants to MFF and PFF adults over 15 days in guava orchard.
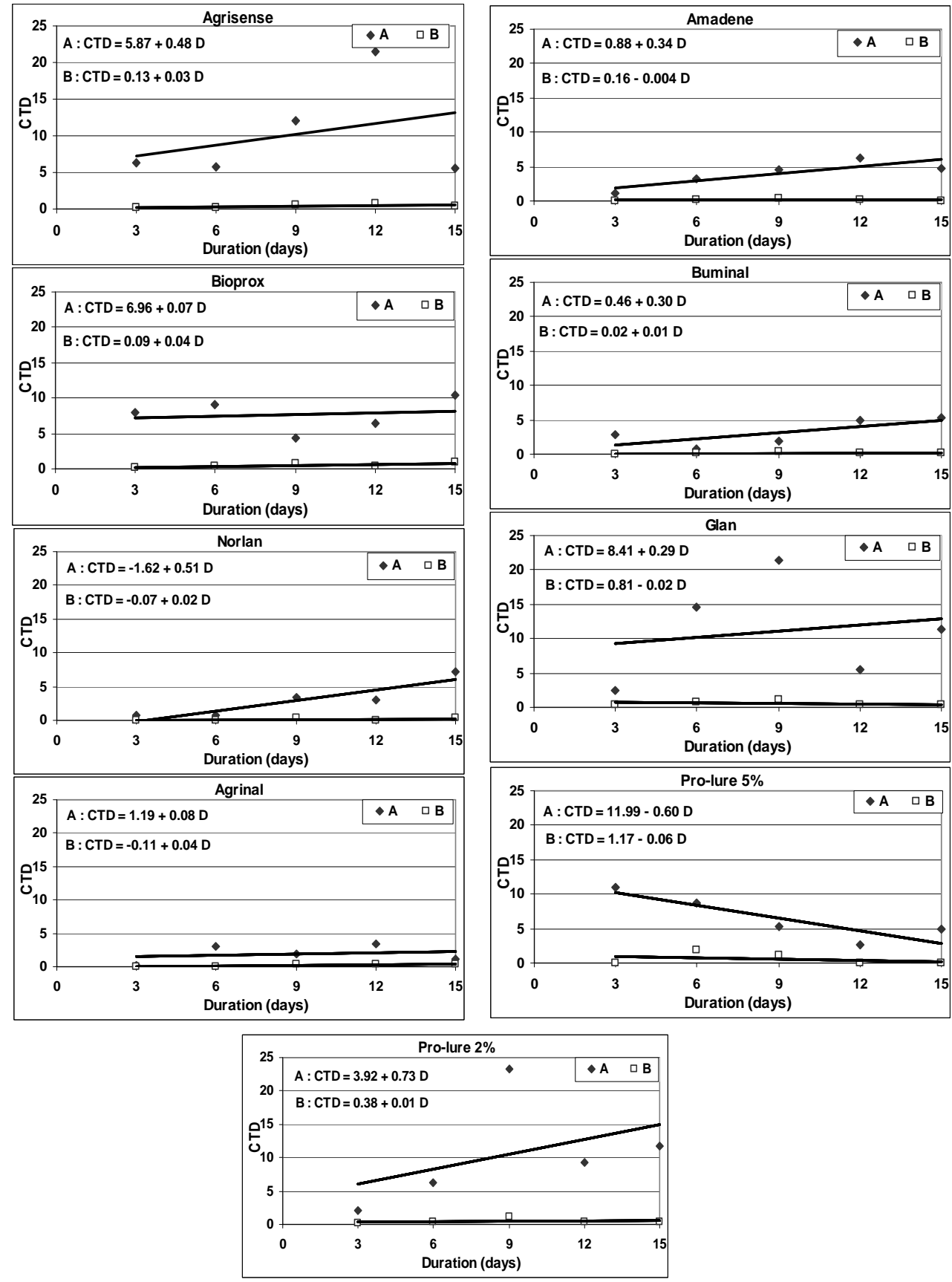

Fig. (3). The relationship between the time (in days) and captured adults (CTD) of MFF (A) and PFF (B) in McPhail traps baited with different food attractants in guava orchards at Mansoura district (bioassayed every three days all over 15 days without renewal the preparations).

Regression analysis illustrated that the attractiveness of MFF adults to the tested food attractants did not affect by the time except that of Norlan. However, the efficiency of Norlan significantly increased by the time.

The relationship between the CTD by Norlan preparation and the time [in days (D)] is described statistically as follow:

$$
\mathrm{CTD}=-1.62+0.51 \mathrm{D}
$$

With respect to $B$. zonata, data illustrated in the figure (3) illustrated that the potentiality of all tested preparations did not affect by the time. However, the time 
pass had not any significant effect on the potentiality of all tested preparations (regression coefficient values were not significantly).

\section{DISCUSSION}

The present investigation indicated that females and males of C. capitata and B. zonata show positive response to the tested food attractants (with differences in their attractiveness). Similar results were obtained by Steyskal (1977), Saafan (2005) and Ghanim (2009) who mentioned that MFF and PFF were attracted to different food attractant preparations. Also, Gopaul and Price (1999), Hanafy et al. (2001), Afia (2007) and Ghanim (2009) mentioned that lures for capturing fruit flies based on food or host odors and liquid protein baits have been used to catch a wide range of different fruit fly species (females and males).

The present results indicated that traps baited with Glan, Pro-lure, Agrisense and Bioprox lured significantly higher number of MFF and PFF adults than the other tested compounds. While, Saafan (2005), Afia (2007) and Ghanim (2009) mentioned that buminal was the main food attractant used in attracting fruit flies. The difference between their results and the present may be attributed to the variation in the tested food preparations.

Toxic sprays containing insect food attractant were previously applied to control fruit flies (Ilardo and Caracci, 1990 and Amin, 2003). However, bait application technique (BAT) deploys spots of protein bait mixed with insecticide, which attract and kill adult fruit flies (Roessler, 1989). The present results showed that adding the pesticide to the food attractant preparations reduced the attractiveness of MFF and PFF adults to these preparations. This may be attributed to the repellent effect of the tested pesticide to the tested insects.

Saafan (2005), Afia (2007) and Moustafa and Ghanim (2008) mentioned that females of MFF and PFF were more attracted to food attractants than males. Also, in the present study, the females were obviously more attracted to all the tested food attractants than males.

The attractiveness of MFF and PFF to the tested food attractants did not affect by the time pass. Where, the efficiency of the tested preparations (except that of Norlan against MFF) did not affect significantly by the time. Similar conclusion was obtained by and Abd El-Kareim et al. (2008); Moustafa and Ghanim (2008) and Ghanim (2009) who mentioned that the efficiency of some ammonium compounds against PFF and MFF did not affect by the time.

Two objectives of using the attractants against fruit flies; the first one, for detecting and monitoring the adult flies (Hanafy et al., 2001; Saafan, 2005 and Ghanim, 2009); the second one, using the attractants for fly control (Roessler, 1989; Permalloo et al., 1998; Amin, 2003; and Ghanim, 2009). So, the tested compounds especially Glan, Pro-lure, Agrisense and Bioprox at 5\% concentration can be used in monitoring populations of fruit flies and in bait application technique (partial bait spray) as a part of integrated control of fruit flies.

\section{REFERENCES}

Abd El-Kareim, A. I; Shanab, L. M.; El-Naggar, M. E. and Ghanim, N. M. (2008). Response of peach fruit fly, Bactrocera zonata (Saunders) (Diptera : Tephritidae) to some ammonium compounds as olfactory stimulants. J. Agric. Sci. Mansoura Univ., 33 (12): 8965-8973. 
Afia, Y. E. (2007). Comparative studies on the biology and ecology of the two fruit flies, in Egypt Bactrocera zonata (Saunders) and Ceratitis capitata (Wiedemann). Ph. D. Thesis, Faculty of Agriculture, Cairo Univ., 301pp.

Aluja, M. (1985). Manejo integrado de las moscas de la fruta 245 pp. Direccion General de Sanidad Vegetal-Secretaria de Agricultura Recursos Hidraulicos. Mexico D.F., Mexico.

Amin, A. A. (2003). Studies on the peach fruit fly, Bactrocera zonata (Saund.) and its control in Fayoum Governorate. M. Sc. Thesis, Fac. Agric., Fayoum University. $127 \mathrm{pp}$.

Anonymous (1985). Buminal fly attractant (lure) Fino work. H. Luithlen Shone Gmbh. and Co. KG. Nahrungsmittle Fabriken. Koblenzer Strabe 58 postfach 180 O-5470 Andernach-Rhein.

Borge, M. N. and T. Basedow (1997). A survey on the occurrence and flight period of fruit fly species (Diptera: Tephritidae) in a fruit growing area in southwest Nicaragua. Bull. Ent. Res., 87 : 405-412.

CoStat Software (1990). Microcomputer program analysis Version 4.2, CoHort Sofware, Berkeley, CA.

El-Minshawy, A. M.; El-Eryan, M. A. and Awad, A. I. (1999). Biological and morphological studies on the guava fruit fly, Bactrocera zonata Saunders) (Diptera: Tephritidae) found recently in Egypt. $8^{\text {th }}$ Nat. Conf. Pests \& Dis. of Veg. \& Fruits in Ismailia, Egypt, 71-82.

Ghanim, N. M. (2009). Studies on the peach fruit fly, Bactrocera zonata (Saunders) (Tephritidae, Diptera). Ph. D. Thesis, Fac. Agric. Mansoura Univ.

Gopaul, S. and Price, N. S. (1999). Local production of protein bait for use in fruit fly monitoring and control. Food and Agricultural Research Council, Réduit, Mauritius, 117-122.

Hanafy, A. H.; Awad, A. I. and Abo-Sheasha, M. (2001). Field evaluation of different compounds for attracting adults of peach fruit fly Bactrocera zonata (Saunders) and Mediterranean fruit fly, Ceratitus capitata (Wied.) in guava orchards. J. Agric. Sci. Mansoura Univ., 26 (7): 4537-4546.

Hashem, A. G.; El-Wakad, M. F. and Soliman, N. A. (2004). The fruit flies. Egyptian Agric. Ministry, The Agricultural Guidance Division. No., 859, 1-35.

Ilardo, G. and Caracci, M. (1990). Supervised control of the olive fruit fly. Informator-Agrario, (46-37), 61-63.

Kapoor, V. C. and Agarwal, M. L. (1982). Fruit flies and their increasing host plants in India. Proc. CEC/IOBC Intern. Symp. Athens/Greece,16-19, November, 1982, pp.252-257.

McPhail, M. (1937). Protein lures for fruit flies. J. Econ. Entomol., 32 (6): 758-761.

Moustafa, S. A. and Ghanim, N. M. (2008). Some ammonium compounds as olfactory stimulants for Mediterranean fruit fly, Ceratitis capitata Wiedemann (Diptera: Tephritidae). J. Agric. Sci. Mansoura Univ., 33 (12): 8965-8973.

Pena, J. E.; Mohyuddin, A. I. and Wysoki, M. (1998). A review of the pest management situation in mango agroecosystem. Phytoparasitica, 26 (2):1-20.

Permalloo, S.; Seewooruthun, S. I.; Joomaye, A.; Soonoo, A. R.; Gungah, B.; Unmole, L. and Boodram, R. (1998). An area wide control of fruit flies in Mauritius. p. 203-210. Proceeding of the Second Annual Meeting of Agricultural Scientist, Reduit, Mauritius, 12-13 August 1997. 
Roessler, Y. (1989). Insecticidal bait and cover sprays. In: Robinson, A. S. Hooper, G. (Eds.), Fruit Flies: their biology, natural enemies and control. Elsevier World Crop pests, Vol., 3 A \& B. Elsevier, Amsterdam, pp. 337-345.

Saafan, M. H. (2000). Field evaluation of some attractants for attracting the adults of Mediterranean fruit fly, Ceratitis capitata (Wied.). Egypt. J. Agric. Res., 78 (1): 97-107.

Saafan, M. H. (2005). Field evaluation of some attractants for attracting the adults of Mediterranean fruit fly, Ceratitis capitata (Wiedemann) and peach fruit fly, Bactrocera zonata (Saunders) in citrus orchards. Egypt. J. Agric. Res., 83 (3): 1141-1156.

Steyskal, G. (1977). History and use of McPhail trap. Fla. Ent., 60 : 11-16.

Syed, R. A.; Ghani, M. A. and Murtaza, M. (1970). Studies on the tephritids and their natural enemies in West Pakistan. III. Dacus zonatus (Saunders) (Diptera: Tephritidae). Tech. Bull. Comm. Wel. Inst. Biol. Cont., 13: 1-6.

White, I. M. and Elson-Harris, M. M. (1994). Fruit flies of economic significance: their identification and bionomics. CAB International with ACIAR. P. 601

\footnotetext{
ARABIC SUMMARY

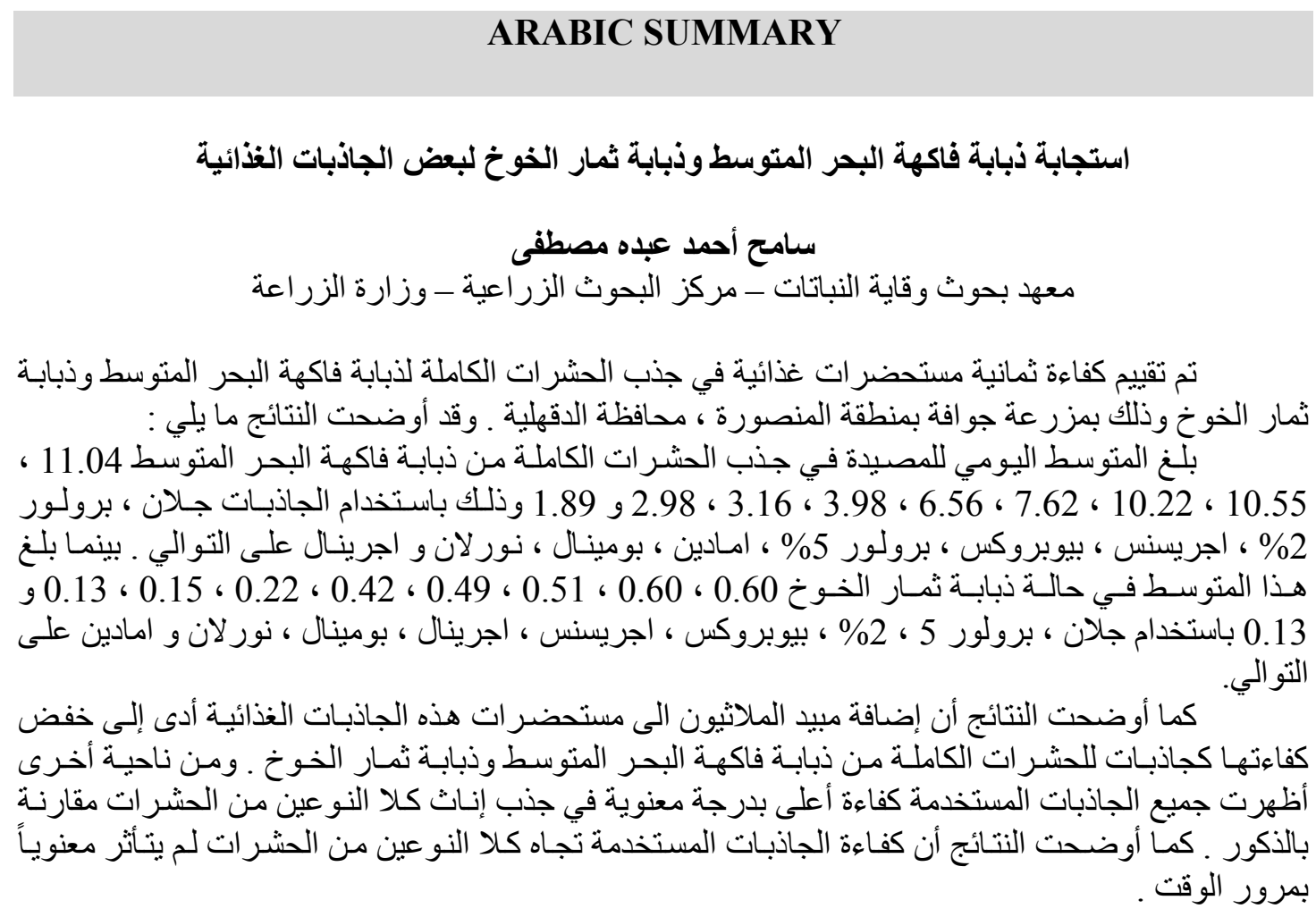

